\title{
EXPERIENCIAS DE MUJERES VÍCTIMAS DE VIOLENCIA OBSTÉTRICA Y DE SUS ACOMPAÑANTES DE LA CIUDAD DE CHILLÁN.
} EXPERIENCES OF WOMEN VICTIMS OF OBSTETRIC VIOLENCE AND THEIR COMPANIONS OF THE CITY OF CHILLÁN.

\section{R E S U M E N}

El presente trabajo describe las experiencias de violencia obstétrica que vivieron mujeres en sus procesos de parto y el rol de sus acompañantes. Se utilizó metodología cualitativa, con un diseño descriptivo de casos múltiples. Se empleó el método biográfico, específicamente relatos de vida recolectados con la técnica de entrevista en profundidad. La muestra se configuró por selección intencional y los datos fueron analizados empleando análisis de contenido. Los resultados principales son que las mujeres experimentaron violencia gineco-obstétrica en la atención de urgencia maternal por alto riesgo obstétrico, en el trabajo de parto, puerperio y post parto. Los acompañantes cumplieron un rol de apoyo permanente, contención afectiva y resguardo del bienestar de sus parejas.

PALABRAS CLAVE: experiencias, violencia obstétrica, funcionarios de salud, mujeres, acompañantes.

\begin{abstract}
A B S T R A C T
The present work describes the experiences of obstetric violence that women lived in their birth processes and the role of their companions. Qualitative methodology was used, with a descriptive design of multiple cases. The biographical method was used, specifically life stories collected with the indepth interview technique. The sample was configured by intentional selection and the data was analyzed using content analysis. The main results are that women experienced gynecological-obstetric violence in maternal emergency care due to high obstetric risk, in labor, puerperium and postpartum. The companions fulfilled a role of permanent support, emotional containment and protection of the well-being of their partners.
\end{abstract}

KEYWORDS: experiences, obstetric violence, health officials, women, companions.

\footnotetext{
"Magíster en Psicología de la Universidad de la Frontera. (Chile). Avenida Andrés Bello S/N. Código Postal: 3780000 , Chillán, Chile. ). Académica Jornada Completa de la Universidad de Los Lagos. Correo electrónico: damaris_opazove@hotmail.com

${ }^{*}$ Psicóloga de la Universidad del Bío-Bío (Chile). Avenida Andrés Bello S/N. Código Postal: 3780000, Chillán, Chile). Afiliada a la Universidad del Bío-Bío, (Chile). Correo electrónico: amanda.ramirezfuentes@gmail.com

*** Licenciada en Psicología de la Universidad del Bío-Bío (Chile). Avenida Andrés Bello S/N. Código Postal: 3780000, Chillán, Chile). Afiliada a la Universidad del Bío-Bío, (Chile). Correo electrónico: casandra21def@gmail.com
} 


\section{INTRODUCCIÓN}

La violencia obstétrica es un problema que atenta contra el derecho a la salud y los derechos reproductivos de las mujeres (Castro y Erviti, 2014). En este contexto, la mujer embarazada es sólo una mera espectadora de los acontecimientos que suceden en su cuerpo, por lo cual no se respeta su capacidad de decidir y participar de su propio parto (Arguedas, 2014). En Chile, el problema es relevante debido a que sólo existe un Proyecto de Ley que establece los derechos de la mujer embarazada durante el trabajo de parto, parto y el post parto, además de sancionar la violencia gineco-obstétrica (2015). En la actualidad el proyecto de ley se encuentra en trámite, por lo cual aún no ha sido discutido en la comisión de Salud de la Cámara de Diputados de Chile.

La discusión nacional en torno al problema se ha vuelto más intensa por lo ocurrido con Adriana Palacios, una joven de 19 años quien denunció que a sus 40 semanas de embarazo vivenció la pérdida de su hija en el útero por sufrimiento fetal, tras habérsele negado en cinco ocasiones la atención asociada a su ingreso a trabajo de parto.
A partir de esta situación, a nivel Nacional se está impulsando el ingreso al Congreso de la "Ley Trinidad" de parto humanizado.

Las preguntas que guiaron esta investigación fueron:

¿Qué experiencias respecto de la violencia obstétrica tienen mujeres que han vivido un proceso de parto?

¿Qué rol cumplen los acompañantes de las mujeres víctimas de violencia obstétrica en sus procesos de parto?

\section{VIOLENCIA OBSTÉ- TRICA}

Las experiencias se conceptualizan como sucesos que personas o grupos sociales viven o han vivido, presentes en la conciencia de éstos y que producen un contacto con emociones, cogniciones, valoraciones y deseos (Avenburg y Martínez, 2014). Se organizan a través del lenguaje, siendo un producto y también un proceso histórico y cultural que forma expresiones, relatos, narrativas, dramas sociales y realizaciones culturales que se muestran y se comunican, es decir, se hacen públicas (Díaz, 1997).

La violencia obstétrica es producto de un entramado multifactorial en donde confluyen tanto la violencia institucional como la violencia de género. Es una forma específica de violencia contra las mujeres que constituye una violación a los derechos humanos. Se 
produce en el ámbito del embarazo, parto y postparto en los servicios de salud públicos y privados y consiste en cualquier acción u omisión por parte del personal del Sistema Nacional de Salud que cause daño físico y/o psicológico a la mujer durante el embarazo, parto y puerperio, expresada en la falta de acceso a servicios de salud reproductiva, un trato cruel, inhumano o degradante, o un abuso de medicalización, menoscabando la capacidad de decidir de manera libre e informada sobre los procesos reproductivos de las mujeres (GIRE, 2015)

Según Villanueva-Egan, (2010) las manifestaciones de violencia obstétrica pueden abarcar desde:

Regaños, burlas, ironías, insultos, amenazas, humillaciones, manipulación de la información y negación al tratamiento, sin referir a otros servicios para recibir asistencia oportuna, aplazamiento de la atención médica urgente, indiferencia frente a sus solicitudes o reclamos, no consultar o informar a las mujeres sobre las decisiones que se van tomando en el curso del trabajo de parto, utilizarlas como recurso didáctico sin ningún respeto a su dignidad humana, el manejo inadecuado del dolor durante el trabajo de parto así como castigo y la coacción para obtener su "consentimiento", hasta formas en las que es posible constatar que se ha causado daño deliberado a la salud de la afectada, o bien que se ha incurrido en una violación aún más grave de sus derechos. (p.148)

Otra manifestación de este tipo de violencia es no respetar los tiempos ni las posibilidades del parto biológico. A nivel psicológico incluye el trato grosero, discriminación, humillación cuando se pide asesoramiento o se requiere atención en el transcurso de una práctica obstétrica, comprendiendo también la omisión de información sobre la evolución de su parto, del estado de salud de su hijo/a y que no se le permita a la mujer ser partícipe de las diversas actuaciones de los funcionarios de la salud. También se consideran prácticas no recomendables la realización de episiotomía, rasurado, monitoreo fetal y enema como prácticas de rutina (Medina, 2009).

En el contexto chileno, el Artículo $4^{\circ}$ del Proyecto de Ley que establece los derechos de la mujer embarazada durante el trabajo de parto, parto y el post parto, además de sancionar la violencia gineco-obstétrica (2015, p. 5) señala:

Violencia Gineco-Obstétrica es aquella que se ejerce contra la 
mujer, por el personal de salud que, la evalúe ginecológicamente o bien de manera obstétrica asistiéndola en el parto, y que se expresa en un trato deshumanizado, en un abuso de medicación y patologización innecesaria de los procesos naturales, que trae como consecuencia para la mujer y en especial la mujer embarazada, la pérdida de su autonomía, y la capacidad de decidir libremente sobre su cuerpo, su sexualidad y reproducción, entre otras (P.5).

Según la Ley $\mathrm{N}^{\circ} 26.485$ de protección integral de las mujeres de Argentina (2009), el trato deshumanizado se caracteriza como un trato cruel, deshonroso, descalificador, humillante o amenazante ejercido por el personal de salud en el contexto de atención del embarazo, parto y postparto.

El Artículo $5^{\circ}$ del Proyecto de Ley chileno (2015, p. 5), puntualiza los actos constitutivos de violencia gineco-obstétrica:

a. No atender oportuna y eficazmente las emergencias ginecoobstétricas.

b. Alterar el proceso natural del parto cuando, de no ser necesario, se aplican técnicas de aceleración, sin obtener el consentimiento voluntario e informado de la mujer. c. Practicar el parto por vía cesárea cuando existen condiciones para el parto natural, sin obtener el consentimiento voluntario e informado de la mujer.

d. Obstaculizar el apego del recién nacido con su madre, sin causa médica justificada, negándole la posibilidad de reconocerlo, cargarlo y amamantarlo inmediatamente después de nacer. e. Proferir insultos, malos tratos físicos y cualquier tipo de violencia psicológica a la mujer embarazada desde el trabajo de parto hasta el post parto.

En Venezuela, el Artículo 51 de la Ley orgánica sobre el derecho de las mujeres a una vida libre de violencia (2007) puntualiza además como acto de violencia obstétrica: "a) Obligar a la mujer a parir en posición supina y con las piernas levantadas, existiendo los medios necesarios para la realización del parto vertical” (p.18).

\section{ROL EN CHILE DE LOS FUNCIONARIOS DE SA- LUD EN LA ATENCIÓN PERSONALIZADA DEL PROCESO REPRODUC- TIVO.}

El Ministerio de Salud de Chile a través del Manual de atención personalizada en el proceso reproductivo (MINSAL, 
2008) especifica los momentos asociados al proceso reproductivo y los roles que los funcionarios de salud encargados de asistir el proceso de gestación, parto y post parto deben cumplir. Estos momentos son:

\section{1. Atención prenatal:}

Atención integral multidisciplinaria hacia la mujer embarazada, con integración de un acompañante significativo. Incluye controles prenatales y talleres prenatales. Los funcionarios de salud deben propiciar que la mujer se encuentre con su acompañante, acogiéndolos empáticamente. Además deben realizar diagnóstico de la condición fetal y estado de la gestación y evaluar posibles riesgos a nivel biomédico, psicosocial, familiar y laboral.

\section{2. Atención de trabajo de parto y parto fisiológico:}

Implica la recepción de la gestante en la unidad de urgencia maternal con el fin de diagnosticar el trabajo de parto y parto para decidir si se efectuará el ingreso al centro hospitalario, abordando eventuales complicaciones y solicitando una evaluación médica de ser necesario. Debe incluirse un acompañante (pareja u otro familiar significativo), a quienes se les debe entregar en forma clara y oportuna información sobre el estado de salud de la mujer y de su hijo/a por nacer, junto con los procedimientos asociados a admisión en urgencias. Los funcionarios de salud deben generar un espacio de intimidad y seguridad en el trabajo de parto y brindar acompañamiento y apoyo psicoafectivo a la mujer y su acompañante, promoviendo una comunicación adecuada con los funcionarios de salud que haga partícipes a los acompañantes de las decisiones a tomar al evaluar la intensidad y tolerancia al dolor de la mujer. Por otra parte, los funcionarios de salud no deben intervenir acelerando el parto si el proceso fisiológico de la mujer evoluciona sin mayores complicaciones, evitando la posición de litotomía para respetar el reflejo de expulsión fetal y no realizar episiotomía de rutina a menos que se considere necesario.

\section{3. Apego precoz:}

Corresponde al fomento del vínculo afectivo entre el recién nacido y la madre. Comprende el apoyo a la madre y su pareja en el inicio de la crianza, favoreciendo conductas que promuevan la formación de un apego seguro. Los funcionarios de salud deben promover la interacción de los padres con su hijo/a y la participación un acompañante (pareja u otro familiar significativo) en el apego, además de brindar 
atención inmediata al recién nacido, controlando los signos vitales de la mujer en el puerperio y post parto.

\section{4. Atención integral durante el postparto:}

El puerperio es la primera etapa del postparto, en la cual la mujer necesita adaptarse a los cambios físicos, psicológicos, sociales que involucra esta etapa, incluyendo el inicio de la lactancia materna. Comienza con la salida de la placenta hasta la regularización de la menstruación de la madre y se subdivide en puerperio inmediato (primeras 24 horas después del parto), puerperio mediato (segundo al décimo día después el parto) y puerperio tardío (extendido hasta 45 días aproximadamente). En esta etapa se llevan a cabo controles a la madre y al lactante, acogiendo empáticamente sus inquietudes y reforzando conductas adecuadas en la relación con el lactante.

\section{5. Postparto:}

Período posterior al parto de duración variable ( 6 a 12 meses). Este período es esencial para la recuperación de la madre y para promover prácticas que permitan establecer un vínculo de apego seguro. Los funcionarios de salud deben educar respecto del autocuidado de la mujer con la participación de un acompañante; orientar acerca de la sexualidad en el post parto y respecto a los métodos anticonceptivos adecuados para este periodo.

\section{DISEÑO DE LA INVES- TIGACIÓN Y METODOLO- GÍA UTILIZADA.}

La investigación se sustentó en el paradigma epistemológico de la fenomenología (Toledo, 2003). Se empleó metodología cualitativa, que corresponde a un modo de investigar los fenómenos sociales que busca comprender la realidad humana y social, orientando la acción humana desde el conocimiento de la realidad subjetiva (Ruiz, 2003), con un Diseño Descriptivo de Casos Múltiples.

Se utilizó el método biográfico y en específico el relato de vida, para acceder a la historia de un proceso o momento particular dentro de una vida tal y como ésta es verbalizada por su protagonista (Rodríguez, Gil y García, 1999).

Para la recolección de la información se emplearon entrevistas en profundidad (Taylor y Bogdan, 2013). Para la realización de las entrevistas en profundidad se empleó un guión de temas que orientaron la indagación en las experiencias de las mujeres y roles de los acompañantes. La guía se construyó considerando las diferentes eta- 
pas que conforman el proceso de embarazo, trabajo de parto, parto y posparto (MINSAL, 2008). El guión integró los siguientes temas:

Embarazo: vivencias de las mujeres en el embarazo y rol del acompañante durante el embarazo.

Atención prenatal: experiencias de las mujeres en la atención prenatal con los funcionarios de salud y rol del acompañante en las atenciones prenatales de salud.

Atención del trabajo de parto: experiencias de las mujeres en el trabajo de parto con los funcionarios de salud y rol del acompañante en el trabajo de parto.

Parto: experiencias de las mujeres en el parto con los funcionarios de salud y rol del acompañante en el parto.

Apego precoz: experiencias de las mujeres en el apego precoz con los funcionarios de salud y rol del acompañante en el apego precoz.

Atención integral durante el postparto: experiencias de las mujeres con los funcionarios de salud en el puerperio inmediato, puerperio mediato, puerperio tardío y rol del acompañante en el puerperio inmediato, puerperio mediato y puerperio tardío.

Post-parto: experiencias de las mujeres en el post-parto con los funcionarios de salud y rol del acompañante en el post-parto.
Para la elección de la población se utilizó la selección intencional (Rodríguez, Gil y García, 1999). La muestra con la cual se trabajó fue la siguiente:

a) Mujer 1, Estudiante Universitaria, 21 años. Las experiencias de violencia obstétrica las vivenció en su primer parto en el sistema público, a los 18 años.

b) Mujer 2, estudiante de Universitaria, 21 años. Las experiencias de violencia obstétrica las vivenció en su primer parto en el sistema público, a los 19 años.

c) Acompañante 1, pareja actual de la mujer 1.

d) Acompañante 2, pareja actual de la mujer 2.

Para el análisis de los datos se utilizó el análisis de contenido, técnica que implica un proceso de identificación, codificación y categorización de los ejes más importantes asociados a los datos recogidos (Ruiz, 2003).

\section{DESCRIPCIÓN Y ANÁ- LISIS DE RESULTADOS}

A continuación se responderá a la pregunta de investigación:

\section{¿Qué experiencias respecto de la violencia obstétrica tienen mu- jeres que han vivido un proceso de parto?}


Previo al ingreso a Atención Prenatal, ambas mujeres respondieron al embarazo con angustia, negación, miedo, rabia hacia la pareja y culpa.

"Ya un día él me dijo que me hiciera el test y me lo hice como tres veces y salían todos positivos y no había forma de negarlo" (Mujer 1).

"Yo estaba enojada, así como que a mí me estaba pasando todo de los síntomas físicos y a él nada, no quería contestarle, con él nada” (Mujer 2).

"Entonces era como que uy me iba a hacer cargo de una guagua y ahí me puse a llorar, me puse a gritar porque era primeriza y tenía miedo" (Mujer 1).

"Fui de vacaciones, fue horrible, no disfruté nada porque estaba mal, me sentía culpable porque les había fallado a mi familia" (Mujer 2).

La respuesta familiar a la noticia del embarazo fue de apoyo familiar hacia una mujer y de rechazo familiar hacia la otra mujer.

"Le conté a mi hermana y se puso a llorar conmigo, dijo que era de felicidad y me dijo que me iba a apoyar en todo si yo quería seguir estudiando" (Mujer 1)
"Mi mamá quería pegarle, como que lo zamarreó y lo echó de la casa a mi pololo y él se fue y yo me tragué todo, me fui pa adentro, quería llorar pero no pude llorar, fue súper triste po, me sentí muy sola en ese momento" (Mujer 2).

Las fuentes de apoyo social importantes para ambas participantes en el embarazo fueron agentes escolares y compañeros de universidad.

"La señora de orientación del colegio me apoyó en todo, me dijo que igual podía seguir estudiando, entonces sentí harto apoyo del colegio" (Mujer 1).

"En la U todos me vieron embarazada y mis compañeros me preguntaban, me tocaban la guata contentos, como que eso me hacía sentir feliz" (Mujer 2).

\section{1. Atención prenatal}

Una vez ingresadas las mujeres participantes al sistema de salud pública a la Atención prenatal en Centro de Salud Familiar (CESFAM), se refiere un trato amable de parte de los funcionarios de salud y entrega de información sobre el estado de salud del bebé y la madre en el proceso gestacional, además de promover la inclusión del 
acompañante en los controles prenatales. Ambas mujeres destacan el involucramiento positivo de sus acompañantes en todos los controles del proceso gestacional, la contención afectiva recibida de parte de ellos y el resguardo permanente que ellos hicieron de su bienestar.

"Él siempre estuvo conmigo, entonces me sentía súper segura, me sentía bien po al lado de él porque sentía angustia y él me tranquilizaba" (Mujer 1).

"Él me decía estoy todo el día preocupado por ti, trabajo para poder juntar la plata, quiero que tengai lo mejor, que la hija tenga lo mejor" (Mujer 2).

Un hallazgo de esta investigación, se asocia a la experiencia de una de las participantes en la Atención de Urgencia Maternal del Hospital donde nació su hijo por su condición de alto riesgo obstétrico. Esta condición no fue diagnosticada oportunamente y su condición delicada de salud gestacional fue minimizada. Al asistir reiterativamente a urgencia maternal, no se resguardó su privacidad en la atención y recibió un trato devaluador asociado a su dolor y sangramiento. Todo esto generó en ella sentimientos de vergüenza, indefensión, angustia y miedo intenso a la pérdida del feto.
"Yo tenía un embarazo de alto riesgo pero a mí nunca me mandaron al programa ARO porque tenía placenta baja, entonces yo iba sola con mi pololo a la emergencia maternal y allá me mandaban para la casa siempre, como lo típico que a uno le dicen que es alharaca, que es primeriza, que no sabe, pero yo iba porque no me podía parar y sangraba altiro, entonces yo pensaba que iba a perder la guagua, me daba un miedo horrible porque me corría la sangre, fue fuerte porque yo era la primera vez que lo vivía y no sabía nada y más encima a una la estaban atendiendo y entraba de repente no sé si era auxiliar, entraba a sacar algo y salía y uno ahí con las piernas abiertas ni siquiera tapadas y la vergüenza horrible porque la puerta daba justo para el pasillo donde había más gente, o de repente me atendía una matrona y aparecía un matrón y le decía venga a ver qué opina usted y yo quedaba mal" (Mujer 1).

\section{2. Atención del trabajo de parto}

En esta instancia la primera participante experimentó dolores agudos producto de la prolongación de su trabajo de 
parto. En el momento en que comienza a expresar su dolor, refiere haber sido maltratada por la mayoría de los funcionarios de salud en su trabajo de parto. El maltrato consistió en descalificaciones verbales, invalidación de su dolor, culpabilización y bofetadas, lo cual genera una vivencia traumática y con ello sentimientos de soledad y abandono de parte de los funcionarios de salud. Además experimentó miedo a la pérdida del bebé y sentimientos de intimidación frente a la imposición de aguantar el dolor.

"Cuando ya estaba con dolores vino más lo traumático porque me dolía mucho y me pusieron suero con medicamentos para inducir el parto y empezar las contracciones entonces yo seguía con los dolores y había una matrona que estaba durmiendo a eso como de las dos de la mañana y yo ya estaba pero muerta, no podía más, estuve como 17 horas en trabajo de parto entonces estaba pero muerta de dolor y nadie me creía, la matrona me decía que era una alharaca, que no dejaba de gritar y que por qué no dejaba dormir a nadie, después fue esa misma matrona y ahí me dijo que qué me pasaba que gritaba tanto y yo le dije que me dolía, que ya no podía más, que no aguantaba y ella me dijo pero cómo, me revisó el suero y me dijo te están calmando el dolor, si tú ya no tienes que tener dolor me dijo y yo le decía gritando sí me duele y al final me cacheteó por los dos lados, y ahí ella me dijo córtala que no puedo dormir y yo le dije pero si me duele y me dijo uy si ahora llaman a la mamá, si tú tuviste la culpa porque te metiste a hacer cosas de grande, entonces fue un trato súper inhumano, pa' mí denigrante porque a mí nunca me pegaron en la vida y ella lo hizo en un momento en que una está súper débil” (Mujer 1).

"Estaba súper asustada porque me dejaron sola, entonces yo tocaba el timbre y nadie venía, estaba súper asustada después de que fue la matrona a pegarme, a mi pololo lo mandaron pa la casa, yo no alcanzaba el velador para llamar a alguien y no me podía ni mover entonces estaba pero aterrada, no sabía qué hacer ni lo que iba a pasar" (Mujer 1).

"Me retaban por todo, del auxiliar hasta el médico todos me repetían lo mismo...que ahora llama a la mamá o que ahora pide ayuda y para hacer la guagua no pidió ayuda o que ahora está débil y cuando estaba haciendo la guagua no y lo que más repetían 
era que tenís que aguantar no más porque si hiciste cosas de grande tenís que aguantártelas" (Mujer 1).

En relación a la segunda participante, ingresó a trabajo de parto en el Hospital aquejada por fuertes dolores por el rompimiento de la bolsa amniótica. La ingresaron tardíamente a trabajo de parto pese a la insistencia del acompañante de que atendieran a su pareja en forma urgente por la intensidad de sus dolores. Experimentó temor a ser maltratada en el trabajo de parto o parto por vivencias reportadas por mujeres conocidas, por lo cual reprimió toda expresión de dolor con tal de no ser maltratada por ningún funcionario de salud.

"Fui al hospital porque se me rompió la bolsa y empecé a botar agua y me dio susto porque era agua con sangre y yo dije oh voy a perder a mi hija, así que ahí me fui al hospital y no nos atendieron altiro, el guardia no dejaba pasar, yo iba en silla de ruedas porque no podía caminar y no querían dejar pasar a nadie $\mathrm{y}$ cuando me atendió la doctora de turno me explicó que yo podía firmar un consentimiento para que me pusieran anestesia la epidural, entonces yo le dije que no quería nada, que quería que fuera todo rápido y yo dije no aguanto media hora más con estos dolores, sentía que la cabeza de la guagua estaba asomada y era horrible, entonces yo le dije a mi pololo anda a buscar a alguien porque yo voy a tener la guagua aquí, entonces él fue a hablar y dijo vengan por favor porque ya va a tener la guagua y ellas lo quedaron mirando y no hicieron nada y entonces volvió porque estaba enojado y asustado po y gritó va a tener la guagua aquí y ahí recién se apuraron me llevaron caminando a la sala de parto" (Mujer 2).

"Yo tenía miedo de que no pudiera tener la guagua y que me retaran, porque yo siempre escuchaba de que a las niñas jóvenes que iban a tener guagua les pegaban, las retaban, les decían cosas, porque había escuchado compañeras del colegio que le pegaron a una o que le decían cosas horribles, entonces yo dije no voy a llorar ni voy a gritar para que no me digan nada ni me hagan nada, no voy a llorar, tampoco quise el suero ni nada y alguien dijo ah esta chiquilla no quiso nada, así como animal lo quiere tener" (Mujer 2). 


\section{3. Asistencia del parto fisioló- gico.}

Ambas mujeres recibieron un buen trato durante el parto por parte de la matrona y el resto del equipo de parto. Este trato fue percibido como humano, destacando como buenas prácticas la entrega de información oportuna asociada a los procedimientos a llevar a cabo con ambas mujeres, la validación de la sensación de dolor en el parto y prácticas de contención en un clima emocional amoroso.

"Bueno todos desde el auxiliar hasta la matrona del parto fueron súper comprensivos conmigo porque igual estaba asustada y la matrona me explicaba todo lo que ella iba a hacer, a mí no me tomó la anestesia entonces me la puso varias veces y ella me decía ¿siente dolor? y sí le decía yo, ya me decía le vamos a poner otra más, esperemos un ratito, me decía que lo estaba haciendo bien o por ejemplo cuando yo iba a pujar ella hacía como los gestos como que ella estaba pujando conmigo entonces me sentía igual más segura, como apoyada por así decirlo, la enfermera igual estaba a un lado de la camilla y al otro lado mi pololo, entonces la enfermera me tomaba la mano o me hacía cariño en el pelo, el auxiliar me pasaba toallitas para secarme la frente, entonces fueron súper humanos, súper comprensivos, el parto fue súper tranquilo" (Mujer 1).

"Y entonces ya y me pusieron y me enseñaron a pujar y como yo me mentalicé a no llorar, a no gritar, nada, como que fue todo súper rápido, como que al tercer puje nació y mientras estaba pujando me dijo la matrona que estaba encargada de recibir la guagüita, me dijo esto es de rutina, le vamos a hacer un corte y me hicieron la episiotomía y de repente me dijo la matrona ahora la vamos a coser aquí me dijo, me dijo le voy a poner anestesia y no me tomó la anestesia y sentí cómo me cosió todo eso y después empezaron las complicaciones, a parte que la posición en la que la tuve es súper incómoda, porque la guagua se sube cada vez que uno respira y es un ardor gigante abajo, como que quema" (Mujer 2).

\section{4. Apego precoz}

El primer contacto con los recién nacidos en ambas mujeres fue percibido como positivo ya que hubo una vivencia de 
apego inmediato entre el bebé, la madre y el acompañante. Existieron sentimientos compartidos entre las mujeres y sus acompañantes como alegría y conexión emocional con su hijo/a.

"Fue lo más hermoso de mi vida, porque lo vi y me lo pusieron $\mathrm{y}$ tuve al tiro el apego con él y me miraba y le hacíamos cariño con mi pololo y él como que nos buscaba igual, fue súper hermoso y las personas que nos atendieron se quedaron ahí, nadie hablaba nada, nadie se movía, era un momento como de nosotros, o sea igual encuentro que ahí hubo como respeto porque dieron el espacio para nos afiatáramos más como familia” (Mujer 1).

"Cuando recién nació me la pusieron acá arriba así...oh la miré sentí su carita, y venía chupándose el dedo y le miré su cara, súper linda su carita y me sentí feliz porque era mía y además su olor, como que me encantó su olor, y si po me sentí súper feliz, no sé, como algo que conectó con ella en ese y yo lo miré a mi pololo y él estaba emocionado, le habían salido unas lágrimas, y es que no pudimos hablar tanto, era como un mensaje implícito, nuestras miradas" (Mujer 2).

\section{5. Atención integral durante el postparto}

\section{5. 1. Puerperio inmediato}

La primera participante vivenció angustia al ver nuevamente a la matrona que ejerció maltrato hacia ella durante el trabajo de parto y temor frente a posible maltrato hacia ella y su hijo recién nacido. Además, comenzó a sufrir molestias físicas producto de la sutura que se le realizó posterior a la episiotomía y experimentó vergüenza a raíz de los comentarios de algunos funcionarios de salud respecto de la apariencia de la sutura. La segunda participante experimentó incomodidad frente a las otras púerperas ya que se le impusieron indicaciones sobre cómo llevar a cabo la lactancia que ella no pudo realizar, generando en ella rabia y deseos de llorar.

"Ella me fue a revisar y me dijo que me destapara el abdomen y ahí cuando le escuché la voz, la miré y ahí vi que era ella y ahí le quise mirar la identificación y no la tenía po y no quise decir nada, no sé si fue por miedo, me puse nerviosa, fue como un montón de cosas, me dieron ganas de llorar, me dieron ganas de llamar a alguien y que me fueran a ver y ahí me destapé y ella me presionó fuerte el abdomen y yo me quejé y me miró feo otra vez y me dijo 
ya listo, y yo me cambié altiro y corría mi guagua pa onde mí si, porque yo dije a la guagua no la toca, a mí me habrá podido hacer lo que quiso, pero a la guagua no" (Mujer 1).

"Mi hija lloraba y estaba justo afuera la estación de enfermería y a cada rato venían a mirarme y me decían pero cómo no vas a saber darle pecho, yo podía darle por un solo lado pero por el otro no, entonces por ese lado que no podía me la ponían fuerte, como que me sentía mal donde yo no sabía hacerlo y me retaban y me dan ganas de llorar pero no lloré pero no era pena, era rabia" (Mujer 2).

\section{5. 2. Puerperio mediato}

Ambas participantes vivenciaron este momento como agotador debido a la persistencia de dolor físico asociado a la episiotomía que se les realizó y como incómodo físicamente dado el inicio del amamantamiento. A la primera participante se le detectó un granuloma en la sutura, por lo cual fue sometida reiterativamente a un procedimiento de quemado de granuloma. La segunda participante, experimentó enojo e irritabilidad y dificultades para dormir debido al dolor que le produjo la episiotomía.
"Mi bebé tenía cinco días cuando fui a urgencias y me dijeron que tenía un granuloma por la mala cicatrización y la mala suturación que me había hecho la matrona en el parto así que tenían que quemarlo, y yo me dio terror po, aparte que el matrón era súper bruto, entonces me decía siéntese ahí, ya abra las piernas y me las abría así él con sus manos y yo aparte que tenía miedo porque me habían dicho que parecía arrollado porque en cualquier momento se me rebanaban los puntos y ahí me mando a comprar nitrato de plata y me empezaron a quemar el granuloma, me lo ponían en la piel, ni siquiera me ponían anestesia, nada, oh era un dolor pero muy grande, horrible y yo seguía yendo a urgencias porque me seguían quemando, fue como una semana que me quemaron" (Mujer 1).

"Al otro día del alta se me abrieron los puntos, se me cortaron y tuve que sacármelos yo, como se me abrieron no alcanzaron a secarse ni nada po, así que me los tuve que tirar yo así, fue doloroso y como me dolía andaba como enojada, irritable, me acuerdo que para el tercer día, después que llegué a mi casa me bajó la leche y me sentía mal porque tenía 
como una gripe, fiebre me dio y además sentía dolor, entonces la primera semana fue súper agotadora, no podía dormir por el dolor" (Mujer 2).

\section{5. 3. Puerperio tardío}

En el período de puerperio tardío, ambas mujeres asistieron a controles con matrona en CESFAM. A la primera participante la matrona le negó la inyección anticonceptiva solicitada por la mujer por falla previa de anticonceptivos orales. La segunda participante consultó por molestias persistentes por la herida de la episiotomía y en control con una enfermera ésta la criticó por no amamantar a su hija para continuar con sus estudios.

"Al final me dijo la matrona yo te doy la inyección pero lo que te pase no es responsabilidad mía, si tú te mueres me dijo por esa inyección y los cambios que haya en tu cuerpo no es responsabilidad mía y me asustó po, no me quería dar la inyección porque yo era muy joven, no dijo eso es pa pura libertad pa andar aquí y allá en la universidad y yo le dije qué tiene que ver que sea joven, además le dije que quería la inyección porque las pastillas me habían fallado y yo estaba estudiando en la universidad" (Mujer 1).
"Tuve controles con la enfermera del consultorio y me dijo yo nunca le di pecho a mis hijos pero yo soy súper fan de la lactancia materna, entonces yo le dije que no podía darle pecho, que no quería, que tenía que seguir en mi carrera entonces ella me dijo o sea que le importa poco su hija y yo le dije que eso no significaba que no me importaba" (Mujer 2).

\section{5. 4. Postparto}

En el post parto la primera participante refiere que su hijo estuvo hospitalizado durante un tiempo y algunos procedimientos fueron aplicados por practicantes con poca experiencia en manejo de lactantes hospitalizados, lo cual generó molestia en el padre ya que la enfermera supervisora no se hizo responsable. La segunda participante señala que la enfermera que la atendió en el centro de salud persistió en criticarla por no amamantar a su hija.

"Mi hijo estuvo hospitalizado una semana y mi pololo tuvo una pequeña pelea ahí con una enfermera porque habían unas niñas en práctica de TENS que les tiritaba la mano cuando inyectaban a mi guagua que tiene las venas súper finitas y ellas no le encontraban la vena y le reventaron dos venas y empezaron a conversar 
entre ellas que casi le pasaron a llevar una arteria, entonces ahí mi pololo se enojó y dijo quién es la encargada de esto porque no iba a dejar que tocaran a su hijo y que lo hiciera alguien responsable y la enfermera encargada se enojó mucho conmigo y con él" (Mujer 1).

"Me tocó esa enfermera pesada en un control y siempre me encontraba algo malo porque no le estaba dando pecho a mi hija, entonces me decía que mi hija no estaba comiendo o me preguntaba por qué no había crecido lo suficiente y me decía de nuevo que era porque yo no quería darle pecho" (Mujer 2).

A continuación se responderá a la pregunta de investigación:

\section{¿Qué rol cumplen los acompañan- tes de las mujeres víctimas de violencia obstétrica en sus pro- cesos de parto?}

Las reacciones iniciales de ambos acompañantes al ser notificados del embarazo de sus parejas fueron de preocupación y temor. Un acompañante contuvo afectivamente la rabia de su pareja y el otro acompañante a pesar de experimentar temor a la reacción de la familia de su pareja, afrontó la situación y conversó con ellos.
"Se puso a llorar, me pegó, me empujó, pero después se relajó porque la abracé y ahí se calmó y bueno yo me preocupé, no sabía qué hacer porque ella estaba estudiando todavía, como se dice me corté todo" (Acompañante 1). "Cuando supimos estábamos los dos, hicimos el test y salió positivo, al principio no le tomé el peso, sino después y me dio miedo antes de ir a hablar con los papás de mi pareja, pero me armé de valor y lo hice (Acompañante 2).

Ambos acompañantes brindaron un trato amoroso permanente hacia sus parejas, apoyándolas durante todo el proceso de gestación y buscaron en forma conjunta con ellas información sobre el embarazo.

"La acompañaba en todo lo que quería, en todo el embarazo, andábamos juntos para todos lados, yo estaba trabajando, pedía permiso o faltaba no más y la acompañaba a los controles, regaloneaba con ella, la atendía, le hacía cariño en la guata" (Acompañante 1).

"A ver yo quería estar con mi pareja y que se sintiera bien y querida y fuimos investigando con ella sobre el embarazo, fuimos 
madurando más el tema pa poder sacarlo a flote" (Acompañante 2).

En relación a los controles prenatales, el primer acompañante cauteló que la matrona que atendía a su pareja la apoyara para que su proceso gestacional transcurriera sin mayores problemas. El segundo acompañante no pudo asistir a los controles por motivos laborales, pero buscó quien la acompañara en su lugar.

"Bueno lo que yo hacía era estar sentado al lado no más porque yo soy bastante vergonzoso digamos, la acompañaba pa todos lados, estuve ahí con ella y me preocupaba de que la matrona la apoyara para que la guagua viniera bien" (Acompañante 1).

"Por pega no podía ir a los controles cuando ella estaba embarazada, porque tenía que saber trabajar y hacer las monedas y yo me preocupaba que fuera con la mamá, pero yo de haber podido hubiera ido, en eso siento que le fallé pero en el resto siempre estuve con ella" (Acompañante 2).

El acompañante de la mujer con embarazo de alto riesgo obstétrico le brindó compañía permanente y apoyo psicológico, a pesar de haber experimentado sentimientos de tristeza por su situación.
"Igual triste porque estaba muy complicada ella, muy adolorida, no podía hacer casi nada porque podía complicarle con el bebé y buta, uno piensa hartas cosas en ese momento pero no, estaba tranquilo, era como si yo me desesperaba iba a desesperarla a ella y se iban a complicar más las cosas, por eso trataba de yo estar siempre alegre, siempre dándole ánimos" (Acompañante 1).

En el ingreso a trabajo de parto, el acompañante de la segunda mujer demandó constantemente revisión médica a su pareja por los dolores agudos que ella sentía por el rompimiento de la bolsa amniótica, experimentando temor frente a posibles complicaciones de salud para su pareja o bebé.

"A mi pareja la llevamos por las contracciones al hospital y la mandaron primero pa la casa, después volvimos al Hospital en la tarde porque se le rompió la bolsa y yo le hablaba a las enfermeras para que le hicieran algo po y no, no me pescaban, ahí estuvieron un buen rato hasta que al final de tanto insistir la pasaron a la sala de parto, pero sentí susto de que pudiera salir algo mal con ella o con mi hija" (Acompañante 2). 
En el parto ambos acompañantes estuvieron presentes, brindaron apoyo emocional a sus parejas y siguieron las indicaciones de los funcionarios de salud para cooperar con el parto de sus parejas.

"Intentaba tomarle la mano pero no quería que nadie la tocara, pero era por lo mismo donde estaba tan nerviosa y eran tantos los dolores y yo la sostenía no más" (Acompañante 1).

"Nunca me imaginé que era tan fuerte todo, porque al verla a ella sufriendo por así decirlo y uno no poder hacer nada te marca, entonces me decían lo que tenía que hacer, le ponía el nitrógeno en la nariz, me explicaron cómo aplicárselo cuando le daban las contracciones, yo estaba apoyándola" (Acompañante 2).

En el apego precoz, ambos acompañantes vivenciaron una experiencia de conexión emocional con sus parejas una vez nacidos sus hijos y establecieron contacto físico con sus recién nacidos. Demostraron un trato amoroso hacia sus parejas y experimentaron relajo y alegría.

"Buta, alegría, una sensación que se siente en el cuerpo, no sé po de tener tu guagua ahí, de verlo, es una alegría que te da, una sensación no tan explicable digamos, pero es bonito, tenerlo ahí cuando nace, yo no había tenido nunca esa experiencia y le di un besito, le hice cariño, todo ya más relajado, como que ahh está aquí, está bien, está sanito y estábamos contentos" (Acompañante 1).

“Oh, lo más lindo que me pudo pasar, tomarla en bracitos, ver que era tan chiquitita, emoción no más po, miedo ya no sentía ya que estaba todo bien" (Acompañante 2).

Respecto al puerperio inmediato, ambos acompañantes indican la necesidad de mayor contacto y conexión emocional con sus hijos.

"Al otro día fui a la hora de visita y estaba desesperado por pasar a verlo, de estar con él y tenerlo en brazos y ahí caminé en la sala con él, le conversaba y como estaba despierto me saqué fotos con él" (Acompañante 1).

"A ver mi hija nació en la tarde y yo lo único que quería era verla para tomarla y hacerle cariñito" (Acompañante 2).

Durante esta etapa, el acompañante de la primera participante sintió la necesidad de proteger a su hijo y se preocupó de acompañar a su pareja a los controles de salud. El acompañante de la segunda participante refiere sentimien- 
tos de culpa por no poder haber podido acompañar a su pareja en el cuidado de su hija.

"Cuando lo llevamos pa la casa yo no quería que nadie metiera boche, no quería que nadie lo molestara, como demasiado protector y también la acompañaba a ella en sus controles y lo único que pensaba era que íbamos a salir adelante con mi hijo y con ella mejor también" (Acompañante 1).

"No sé, como que falta una parte en la historia, me faltan esas trasnochadas heavy con mi hija que se las ha llevado mi pareja sola, $\mathrm{y}$ eso igual me da culpa porque no vivíamos juntos” (Acompañante 2).

En el puerperio tardío el acompañante de la primera participante vivenció en forma positiva el crecimiento de su hijo, mientras que el acompañante de la segunda participante refiere haber sido maltratado junto a su pareja por una enfermera en torno al tema de la lactancia.

"Bueno él estaba más grande, hacia más cosas, uno va viendo cómo va creciendo y se siente bien cuando hacen alguna tontera algún gesto o algo" (Acompañante 1).
"Sí, estaba siempre con ella y la acompañé al control de mi hija con una enfermera y el trato fue malo, retaba a mi pareja por cualquier cosa, por ejemplo reaccionó mal cuando la obligaba a hacer cosas que no se podían hacer tampoco, como no darle pecho a la guagua por los estudios de mi pareja” (Acompañante 2).

En el post parto ambos acompañantes asisten a los diversos controles médicos correspondientes a esta etapa junto con su parejas, brindándose apoyo mutuo. El acompañante de la primera mujer denunció una mala práctica efectuada a su hijo en contexto de hospitalización con el fin de protegerlo.

"Siempre nos apoyamos con mi pareja pero cuando vi a mi hijo así enfermo, puta sentí rabia e impotencia de no poder hacer nada y exigí que la enfermera que supervisara a las practicantes que inyectaron mal a mi hijo me diera explicaciones porque hicieron mal las cosas, siempre protegiéndolo" (Acompañante 1).

"Si mi relación con ella siempre fue buena, yo la acompañaba a sus controles pero la espinita fue la enfermera pesada porque retó a mi pareja porque no quería 
amamantar a mi hija y ella lo habría hecho, pero tenía que seguir estudiando, así que yo le dije que no la siguiera retando" (Acompañante 2).

\section{CONCLUSIONES}

Ambas mujeres vivenciaron experiencias que de acuerdo al Proyecto de Ley chileno que establece los derechos de la mujer embarazada durante el trabajo de parto, parto y post-parto (2015) se enmarcan en lo que se caracteriza como violencia gineco-obstétrica:

-En el caso de la mujer cuyo embarazo fue de alto riesgo obstétrico, en el contexto hospitalario no se atendió en forma oportuna y eficaz las emergencias ginecológicas en el transcurso de su embarazo (dolor y sangramiento permanente), siendo devaluada en relación a su condición delicada de salud, lo cual generó en ella sentimientos de indefensión, angustia y miedo permanente a la pérdida de su hijo en gestación.

-En el trabajo de parto una de las mujeres participantes recibió insultos y maltrato físico, siendo culpabilizada por distintos funcionarios de salud por expresar su dolor físico e intimidada frente a la imposición violenta de “aguantar” su dolor, generando en ella sentimientos de soledad, abandono, indefensión, miedo al actuar de los funcionarios frente a su necesidad de alivio del dolor y temor a la pérdida de su hijo, calificando este trato como inhumano y denigrante. La segunda participante no fue atendida en forma oportuna en el ingreso a trabajo de parto a pesar de la intensidad de sus dolores y el temor a ser maltratada a través de retos o golpes por cualquier funcionario de salud movilizó en ella la necesidad de reprimir el dolor a pesar de haberlo experimentado. Tras la decisión de tener a su hija sin anestesia por lo inminente del parto, fue humillada verbalmente al ser considerada "animal" por haber rechazado la anestesia.

-En el parto, a ambas mujeres una vez que nacieron sus hijos se les aplicó como procedimiento de rutina la episiotomía sin el consentimiento de ninguna. Esto generó consecuencias importantes a nivel físico y psicológico que influyeron en la vivencia del puerperio mediato como un momento doloroso y agotador.

-En el puerperio inmediato, una participante experimentó temor $\mathrm{y}$ angustia al tener nuevamente contacto con la matrona que la insultó y golpeó en el trabajo de 
parto, generando en ella miedo a que pudieran dañar a su hijo recién nacido. La segunda participante recibió retos y humillaciones por "no saber" cómo amamantar a su hija, en circunstancias de adaptación inicial a la lactancia.

-En el puerperio tardío una participante vivenció críticas de parte de una funcionaria de salud por solicitar inyección anticonceptiva, siendo intimidada por la misma funcionaria respecto de las supuestas consecuencias sobre su salud física que traería consigo utilizar la inyección. Con respecto a la decisión de no amamantar de la segunda participante, recibió críticas de parte de una funcionaria de salud, quien interpretó la decisión de la mujer como una muestra de indiferencia frente a las necesidades de su hija. Ambas mujeres experimentaron sentimientos de temor y rabia ya que no se consideró el hecho de que ambas participantes necesitaban continuar con sus estudios universitarios, razón por la cual decidieron responsablemente no seguir las indicaciones de las funcionarias.

-En el post-parto una participante vivenció la hospitalización de su hijo, quien fue inyectado por practicantes de enfermería sin supervisión de una enfermera profesional, generando con ello rabia por el riesgo al cual expusieron a su hijo al aplicarle mal una inyección. La segunda participante vivenció nuevamente críticas por no amamantar a su hija y la funcionaria de salud atribuyó en forma arbitraria las dificultades en el crecimiento de la lactante a la privación de la leche materna.

-Según Villanueva-Egan (2010) y Medina (2009) ambas mujeres vivieron las siguientes manifestaciones de vivencia obstétrica durante el embarazo, trabajo de parto, parto y post parto: regaños, burlas, ironías, amenazas, humillaciones, negación al tratamiento sin referir a otros servicios para recibir asistencia oportuna, aplazamiento de la atención médica urgente, indiferencia frente a sus solicitudes, no consultar sobre las decisiones que se van tomando en el trabajo de parto en virtud de la intensidad del dolor, manejo inadecuado del dolor en el trabajo de parto e imposición de procedimientos sin el consentimiento de las mujeres. Todo lo anterior, condujo a una pérdida de autonomía e indefensión permanente en ellas y a una 
invalidación de su capacidad de decidir libremente sobre su cuerpo, sexualidad y reproducción, incluso en decisiones que las mujeres debieron tomar en el post parto.

-Si bien ambas mujeres vivenciaron experiencias de violencia gineco-obstétrica, fueron capaces de identificar buenas prácticas en algunos momentos de su proceso reproductivo (MINSAL, 2008). Estos momentos fueron los siguientes: Atención prenatal en Centro de Salud Familiar (controles prenatales en CESFAM, correspondiente al nivel de atención primaria de salud); en este momento se destaca el trato amable de parte de los funcionarios de salud, la entrega de información respecto de la salud de sus hijos y la promoción de la inclusión activa de sus acompañantes en las atenciones prenatales. El parto fue el segundo momento en que se destacan buenas prácticas en específico hacia una participante ya que en este momento se le entregó información oportuna respecto a los procedimientos a llevar a cabo con ella, se validó su dolor para la toma de decisiones que condujeran a la disminución del dolor considerando la perspectiva de la propia mujer; se promovió la inclusión del acompañante como apoyo psicoafectivo en el parto y se realizaron prácticas de contención dentro de un clima emocional amoroso y preocupado por el bienestar de la mujer. El tercer momento en donde hubo buenas prácticas fue el apego precoz; en este momento los equipos de parto promovieron el contacto físico y conexión emocional entre madre, hijo y acompañante en un clima de respeto a la intimidad familiar.

-Ambas mujeres concluyen que las principales figuras de apoyo durante el embarazo, trabajo de parto, parto, puerperio y post parto fueron sus acompañantes, en ambos casos sus parejas. Éstos se involucraron en forma positiva en todas las atenciones recibidas por las mujeres, conteniéndolas afectivamente y resguardando permanentemente su bienestar.

-Respecto del rol de los acompañantes en la relación con las mujeres participantes desde la perspectiva de ellos, se puede destacar: la contención afectiva hacia las participantes sobretodo en momentos con alta carga de angustia; el trato amoroso permanente hacia sus parejas durante el proceso gestacional y acompa- 
ñamiento en las atenciones prenatales. En el caso del acompañante de la mujer con embarazo de alto riesgo obstétrico, el apoyo psicológico brindado a su pareja fue crucial, a pesar de haber experimentado sentimientos de preocupación y tristeza.

-En el trabajo de parto los acompañantes llevaron a cabo acciones que cautelaron dentro de lo posible el bienestar de sus parejas y sus hijos por nacer, brindando una respuesta sensible al dolor de ellas a pesar de que ellos experimentaron sentimientos de temor y rabia. En el parto, ambos acompañantes estuvieron presentes, brindaron apoyo emocional a sus parejas y siguieron las indicaciones de los funcionarios de salud para cooperar en el parto. En el apego precoz, experimentaron sentimientos de felicidad y conexión con sus hijos recién nacidos y con sus parejas, buscando tener mayor contacto con sus hijos y apoyar a sus parejas en su adaptación al puerperio. Finalmente, en el puerperio y post parto se preocuparon de acompañar a sus parejas a los controles de salud y de validar sus decisiones en torno a su autocuidado, en un contexto en el cual tanto las mujeres como sus acompañantes se brindaron apoyo mutuo.

\section{REFERENCIAS BIBLIOGRÁFICAS}

Arguedas, G. (2014). La violencia obstétrica: propuesta conceptual a partir de la experiencia costarricense. Cuadernos intercambio sobre Centroamérica y el Caribe, 11(1), 145- 169. Recuperado de http://www.redalyc.org/pdf/4769/47694724100 8.pdf

Averburg, K. y Martinez, B. (2014). Experiencias e interpretaciones en performances rituales (Iruya y EI Cajón, noroeste argentino). Cuadernos de antropología social, 39, 115-147. Recuperado de http://www.scielo.org.ar/pdf/cas/ n39/n39a05.pdf

Castro, R. y Erviti, J. (2014). 25 años de investigación sobre violencia obstétrica en México. Revista CONAMED, 19(1), 37-42. Recuperado de file://Users/damarisopazovega/Downloads/Dialnet25AnosDelnvestigacionSobreViolenciaObstetricaEnMex4730781.pdf

MINSAL (2008). Manual de atención personalizada en el proceso reproductivo. Recuperado de 
http://web.minsal.cl/por-

tal/url/item/795c63caff4fde9fe04 001011f014bf2.pdf

Díaz, R. (1997). La vivencia en circulación. Una introducción a la antropología de la experiencia. Alteridades, 7(13), 5-15. Recuperado de http://www.redalyc.org/pdf/747/74711130002.p $\mathrm{df}$

GIRE (2015). Violencia obstétrica. Un enfoque de derechos humanos. Recuperado de https://gire.org.mx/wp-content/uploads/2016/07/informeviolenciaobstetrica2015.pdf

Ley orgánica sobre el derecho de las mujeres a una vida libre de violencia (2007). Recuperado de http://www.dere-

chos.org.ve/pw/wp-content/uploads/11.-Ley-

Org\%C3\%Alnica-sobre-el-Derecho-de-las-Mujeres-a-una-VidaLibre-de-Violencia.pdf

Ley 26.485 (2009). Ley de protección integral de las mujeres. Recuperado de https://www.oas.org/dil/esp/Ley_ de_Proteccion_Integral_de_Mujeres_Argentina.pdf

Medina, G. (2009). Violencia obstétrica. Revista de Derecho de Fa- milia y de las Personas. Recuperado de http://www.gracielamedina.com/articulos-publica$\mathrm{dos} /$ ?start $=232$

Proyecto de Ley que establece los derechos de la mujer embarazada durante el trabajo de parto, parto y el post parto, además de sancionar la violencia ginecoobstétrica (2015). Recuperado de http://ovochile.cl/wp-content/uploads/2015/05/ProyectoLey-Violencia-

Obst\%C3\%A9trica.pdf

Rodríguez, G., Gil, J. y García, E. (1996). Metodología de la investigación cualitativa. Málaga: Ediciones Aljibe.

Ruiz, J. (2003) Metodología de la investigación cualitativa. Bilbao: Universidad de Deusto.

Taylor, S. y Bogdan, R. (2013). Introducción a los métodos cualitativos de investigación. Barcelona: Paidós.

Toledo, U. (2003). Fenomenología del Mundo Social. ¿Un programa de investigación Científico? Cinta moebio, 18, 191-206. Recuperado de http://www.cintademoebio.uchile.cl/index.php/CDM/article/viewFile/26137/27435 
Villanueva-Egan, L. (2010). El maltrato en las salas de parto: reflexiones de un gineco-obstetra. Revista CONAMED, 15(3), 147-151. Recuperado de file:///Users/damarisopazovega/Downloads/DialnetEIMaltratoEnLasSalasDeParto3393251\%20(3).pdf

\section{PARA CITAR ESTE ARTÍCULO:}

Opazo, D., Ramírez, A., y Chamorro, C. (2017). Experiencias de mujeres víctimas de violencia obstétrica y de sus acompañantes de la ciudad de Chillán. Collectivus, Revista de Ciencias Sociales, 4(2), 78-102.

DOI: http://dx.doi.org/10.15648/Coll.2.2017.5

Recibido: 10/03/2017 Aprobado: 18/05/2017 